\title{
Facile Preparation of Copper(I) Halide-Dimethyl Sulfide Complex and Its Application
}

\author{
Il-Hyun Park, Myung Sub So, ${ }^{\star}$ and Koon Ha Park*
}

\author{
Division of Chemistry \& Biochemistr, Chungnam National Lniversin, Daejeon 305-764, Korea. "E-mail: khparkiâcnuackr \\ ${ }^{\dagger}$ Gunsan Jeil High School, Gunsan. Jeonbuk $573-410$. Korea \\ Received February 26. 2007
}

\begin{abstract}
A preparative method of $\mathrm{Me}_{2} \mathrm{SCuX}(\mathrm{X}=\mathrm{Cl} . \mathrm{Br})$ via one-pot reaction was developed from conmon chemicals such as benzyl halide. DMSO. and $\mathrm{Cu}(0)$. In the reaction mixture small molecules such as methyl halide and dimethyl sulfide etc. were efficiently generated in situ. resulting in the formation of $\mathrm{Me}_{2} \mathrm{SCuX}$. Oxidation of $\mathrm{Cu}(0)$ in reacting with both benzyl halide (starting material) and methyl halide (in situ generated product) to $\mathrm{Cu}(\mathrm{I})$ followed by complexing with dimethyl sulfide (in sin generated product) could explain the formation of $\mathrm{Me}_{2} \mathrm{SCuX}$. In particular we found out that heterogeneous reaction of $\mathrm{Me}_{2} \mathrm{SCuX}$ and arenediazonium tetrafluoroborate in acetonitrile was so effective to afford corresponding bromoaronatics under mild conditions.
\end{abstract}

Key Words : Copper(I) halide-dimethyl sulfide complex. DMSO. Benzyl halide

\section{Introduction}

Copper(I) halide-dimethyl sulfide complex (Me $\mathrm{SCuX}$ X $=\mathrm{Cl}$. Br) has been utilized in organic reactions as a versatile reagent. Among the many examples, use of $\mathrm{Me}_{2} \mathrm{SCuX}$ to prepare organocuprates seents to be a representative. ${ }^{1}$ $\mathrm{Me}_{2} \mathrm{SCuX}$ is also known to exert catalytic activities in reactions such as in isomerization of 3.4-dichloro-1-butene to 1,4-dichloro-2-butene. ${ }^{2}$

Though conmercially available $\mathrm{Me}_{2} \mathrm{SCuX}$ might seem to serve the purposes in general. when much purer $\mathrm{Me}_{2} \mathrm{SCuX}$ is required, it needs to be freshly and carefully prepared to avoid side reactions resulting from the presence of impurities such as $\mathrm{Cu}$ (II) and other metal salts. In regards to this House et al described that lithium organocuprate reagents. made from organolithium and $\mathrm{Cu}(\mathrm{I})$ salt, were decomposed by small amounts of other metal salts such as $\mathrm{Cu}$ (II) during the process of preparing thermally unstable cuprates. $^{3}$

Considering that the general preparative method of $\mathrm{Me}_{2} \mathrm{SCuX}$ requires both $\mathrm{Me}_{2} \mathrm{~S}$ and $\mathrm{CuX}$, these impurities are obviously originated from the $\mathrm{CuX}$, as was documented in the literature. That is. Wuts described that rather old and impure samples and even some freshly supplies of $\mathrm{CuBr}$ contained various amounts of impurities, presumably $\mathrm{CuBr}$ : and various oxides. And he suggested that these impurities in $\mathrm{CuBr}$ were quite soluble in methanol and therefore could readily be washed out. ${ }^{4}$ And he used purified $\mathrm{CuBr}$ to make Me $S C$ CuX. However Theis et al. dissatisfied with the previous method comprising tedious steps to remove colored impurities such as $\mathrm{Cu}_{2}, \mathrm{CuX}_{2}$, and oxides present in $\mathrm{CuX}$. proposed an another method that $\mathrm{CuBr}$ free of other impurities might be obtained by reducing $\mathrm{CuBr}$ : with sodium sulfite. ${ }^{\xi}$

Recently Park et al. reported that trimethylsulfonium bromide was obtained from a solution of benzyl bromide in DMSO upon heating. ${ }^{6}$ And they proposed that in sinu generated dimethyl sulfide and methyl bromide resulted the formation of trimetlyylsulfonium bromide. Herein we would like to report a preparative method of $\mathrm{Me}_{2} \mathrm{SCuX}$ by adding $\mathrm{Cu}(0)$ to the aforementioned solution of benzyl halide in DMSO. Looking into the literature there is a precedent publication very similar to our findings but using either inorganic acid (HX) or alkyl halides instead of benzyl halides we used. ${ }^{7}$ The Me $\mathrm{SC}_{2} \mathrm{SCX}$ prepared by our method was satisfactorily pure. readily discerned by its color as was described earlier by House et al.. i.e. each of $\mathrm{CuCl}_{2}$ and $\mathrm{CuBr}_{2}$ forms dark green and dark red solution respectively with dimetlyyl sulfide. ${ }^{3}$

In addition to this we have found out that $\mathrm{Me}_{2} \mathrm{SCuBr}$ prepared by this method was very effective in displacing diazonium tetrafluroborate group to afford bromoaromatics particularly under mild conditions. That is, the reactions were completed within $5 \mathrm{~min}$ at room temperature under neutral organic media (refer results and discussions).

\section{Experimental Section}

Marerials. Unless stated otherwise, most of reagents were prepared and some of reagents and solvents purchased were used as received without further purification.

Preparation of $\mathrm{Me}_{2} \mathrm{SCuX}(\mathrm{X}=\mathrm{Cl}, \mathrm{Br})$. Standard procedure (using benzyl bromide). To a solution of benzyl bromide $(2.38 \mathrm{~mL}, 20 \mathrm{mmol})$ in DMSO $(10 \mathrm{~mL})$ was added $\mathrm{Cu}(0)(0.64 \mathrm{~g} .10 \mathrm{mmol})$. The reaction mixture was maintained at $120^{\circ} \mathrm{C}$ for $5 \mathrm{~h}$. After the solution was cooled to room temperature was added water until no more solid appeared. The complex $\mathrm{Me}_{2} \mathrm{SCuBr}$ was separated just by decantation. The complex obtained was stirred in acetone to remove DMSO. followed by filtration. The pale silver crystalline complex was dried under vacuum and weighed (1.58 g. $77 \%$ ). mp $127.129^{\circ} \mathrm{C}$ (dec) (lit ${ }^{3} \mathrm{mp} 124-129^{\circ} \mathrm{C}$ (dec.)): ${ }^{~} \mathrm{H}$ NMR (DMSO- $c k$ ) $\delta 2.1$ (s): IR (KBr) 2991. 2919. 1438. 1417. 1040. 987. 
Using benzyl chloride. The standard procedure above was repeated except benzyl chloride $(2.40 \mathrm{~mL}$. $20 \mathrm{mmol})$ instead of benzyl bromide to give complex $\mathrm{Me}_{2} \mathrm{SCuCl}(0.30 \mathrm{~g}$. $19 \%$ ). mp $120-125^{\circ} \mathrm{C}$ (dec.) (lit $\mathrm{mp} 118-124^{\circ} \mathrm{C}$ (dec.)): ${ }^{1} \mathrm{H}$ NMR (DMSO- $\left.d_{6}\right) \delta 2.0(\mathrm{~s})$.

Using 4-methylbenzyl bromide. The standard procedure above was repeated except the use of 4-methylbenzyl bromide $(0.93$ g. $5.0 \mathrm{mmol})$. DMSO $(4.0 \mathrm{~mL})$ and $\mathrm{Cu}(0)$ $(0.16 \mathrm{~g})$ to give $\mathrm{Me}_{-} \mathrm{SCuBr}(0.45 \mathrm{~g} .88 \%)$.

Using 2-methylbenzyl bromide. The standard procedure above was repeated except the use of 2-methylbenzyl bromide $(1.34 \mathrm{~mL}, 10 \mathrm{mmol})$. DMSO $(8.0 \mathrm{~mL})$ and $\mathrm{Cu}(0)$ $(0.32 \mathrm{~g})$ to give $\mathrm{Me}_{-} \mathrm{SCuBr}(0.91 \mathrm{~g} .89 \%)$

Using 2-chlorobenzyl bromide. The standard procedure above was repeated except the use of 2-chlorobenzyl bromide $(1.30 \mathrm{~mL}, 10 \mathrm{mmol})$, DMSO $(8.0 \mathrm{~mL})$ and $\mathrm{Cu}(0)$ $(0.32 \mathrm{~g})$ to give $\mathrm{Me}-\mathrm{SCuBr}(0.80 \mathrm{~g} .78 \%)$

Using 4-nitrobenzyl bromide. The standard procedure above was repeated except the use of 4-nitrobenzyl bromide $(2.17 \mathrm{~g} .10 \mathrm{mmol})$, DMSO $(8.0 \mathrm{~mL})$ and $\mathrm{Cu}(0)(0.32 \mathrm{~g})$ to give $\mathrm{Me}_{2} \mathrm{SCuBr}(0.87 \mathrm{~g} .85 \%)$.

Using 2-nitrobenzyl bromide. The standard procedure above was repeated except the use of 2-nitrobenzyl bromide $(2.17 \mathrm{~g} .10 \mathrm{mmol})$, DMSO $(8.0 \mathrm{~mL})$ and $\mathrm{Cu}(0)(0.32 \mathrm{~g})$ to give $\mathrm{Me}_{2} \mathrm{SCuBr}(0.89$ g. $87 \%)$.

\section{Preparation of diazonium tetrafluoroborate ${ }^{8}$}

Benzenediazonium tetrafluoroborate (standard procedure): To a $250 \mathrm{~mL}$ two-neck round-botton flask was added aniline $(6.6 \mathrm{~mL} .72 .5 \mathrm{mmol})$, conc. $\mathrm{HCl}(30 \mathrm{~mL})$ and water $(15 \mathrm{~mL})$, followed by heating for $30 \mathrm{~min}$. After the reaction mixture was cooled to $0-5^{\circ} \mathrm{C}$ using ice-bath, solution of sodium nitrite $(6.0 \mathrm{~g}, 87 \mathrm{mmol})$ in water $(20 \mathrm{~mL})$ was added dropwise. When the addition was completed, any insoluble solid was filtered off, followed by addition of sodium tetrafluoroborate $(15.8 \mathrm{~g} .145 \mathrm{mmol})$. The precipitate was filtered, washed with cold water, ethanol and ether respectively to obtain pale beige crystalline solid $(9.76 \mathrm{~g}$. $57 \%$ ). mp $98-102^{\circ} \mathrm{C}$ (dec.).

3-Nitrobenzenediazonium tetrafluoroborate: The standard procedure above was repeated except the use of 3-nitroaniline $(10.0 \mathrm{~g} .72 .5 \mathrm{mmol})$ to obtain pale beige crystalline solid (14.8 g. 87\%). mp $161-167^{\circ} \mathrm{C}$ (dec.).

4-Bromobenzenediazonium tetrafluoroborate: The standard procedure above was repeated except the use of 4bromoaniline (12.47 g. $72.5 \mathrm{mmol}$ ) to obtain pale beige crystalline solid $(13.6 \mathrm{~g} .80 \%)$. mp $113-115^{\circ} \mathrm{C}$ (dec)

3,4-Dimethylbenzenediazonium tetrafluoroborate: The standard procedure above was repeated except the use of 3.4-dimethylaniline ( $8.78 \mathrm{~g} .72 .5 \mathrm{mmol}$ ) to obtain pale beige crystalline solid $\left(5.0 \mathrm{~g} .30 \%\right.$ ). $\mathrm{mp} 94-96^{\circ} \mathrm{C}$ (dec.).

4-Nitrobenzenediazonium tetrafluoroborate: The standard procedure above was repeated except the use of 4-nitroaniline $(10.0 \mathrm{~g} .72 .5 \mathrm{mmol})$ to obtain pale beige crystalline solid $(17.0$ g. $99 \%) . \mathrm{mp} 138-141{ }^{\circ} \mathrm{C}$ (dec.): ${ }^{1} \mathrm{H}$ NMR $\left(\right.$ DMSO $\left.-d_{6}\right) \delta 9.0(\mathrm{dd}, J=9.5 \mathrm{~Hz}, J=2.4 \mathrm{~Hz} .2 \mathrm{H}) .8 .8(\mathrm{dd} . J$ $=9.5 \mathrm{~Hz}, J=2.4 \mathrm{~Hz} .2 \mathrm{H}$ ).

3-Chloro-6-methoxy-4-nitrobenzenediazonium tetrafluoro- borate: The standard procedure above was repeated except the use of 3-chloro-6-methoxy-4-nitroaniline (7.30 g. 36.3 mmol). sodium nitrite $(3.0 \mathrm{~g} .43 .5 \mathrm{mmol})$, and sodium tetrafluoroborate $(7.90 \mathrm{~g} .72 .5 \mathrm{mmol})$ to obtain pale beige crystalline solid ( $\left(.83 \mathrm{~g} .20 \%\right.$ ). mp $153.155^{\circ} \mathrm{C}$ (dec.).

2-Methoxylbenzenediazonium tetrafluoroborate: The standard procedure above was repeated except the use of 2methoxyaniline $(8.78 \mathrm{~g} .72 .5 \mathrm{mmol})$ to obtain pale beige crystalline solid (1.43 g. $16 \%$ ).

4-Methylbenzenediazonium tetrafluoroborate: The standard procedure above was repeated except the use of 4methylaniline $(8.78 \mathrm{~g} .72 .5 \mathrm{mmol})$ to obtain pale beige crystalline solid $(2.48 \mathrm{~g} .32 \%)$.

4-Methoxybenzenediazonium tetrafluoroborate: The standard procedure above was repeated except the use of 4 . methoxylaniline ( $8.78 \mathrm{~g} .72 .5 \mathrm{mmol}$ ) to obtain pale beige crystalline solid (1.61 g. 18\%).

Displacement of diazonium tetrafluoroborate group by $\mathrm{Me}_{2} \mathrm{SCuX}(\mathrm{X}=\mathrm{Cl}, \mathrm{Br})$

From benzenediazonium tetrafluoroborate (standard procedure): To a $100 \mathrm{~mL}$ two-neck round-bottom flask was added benzenediazonium tetrafluoroborate $(0.93 \mathrm{~g} .4 .85$ mmol) dissolved in acetonitrile $(20 \mathrm{~mL})$, followed by addition of $\mathrm{Me}_{2} \mathrm{SCuBr}(1.0 \mathrm{~g}, 4.85 \mathrm{mmol})$ under stirring. The solution was concentrated, followed by addition of ethyl acetate. After the insoluble material was filtered off the filtrate was concentrated followed by columu chromatography to obtain bromobenzene $(0.57 \mathrm{~g}, 75 \%)$.

From 3-nitrobenzenediazonium tetrafluoroborate: The standard procedure above was repeated except the use of 3 nitrobenzenediazonium tetrafluoroborate $(1.15 \mathrm{~g}$. 4.85 mumol) to obtain 3-bromonitrobenzene $(0.72 \mathrm{~g} .73 \%) . \mathrm{mp}$ $53-54^{\circ} \mathrm{C}$ (lit. mp $53-56^{\circ} \mathrm{C}$ ).

From 4-bromobenzenediazonium tetrafluoroborate: The standard procedure above was repeated except the use of 4bromobenzenediazonium tetrafluoroborate $(1.3 \mathrm{l} \mathrm{g}, 4.85$ numol) to obtain 1.4-dibromobenzene ( $0.89 \mathrm{~g} .78 \%$ ). $\mathrm{mp} 88$ $89^{\circ} \mathrm{C}$ (lit. mp $83-87^{\circ} \mathrm{C}$ ): ${ }^{1} \mathrm{H}$ NMR (DMSO- $d_{6}$ ) $\delta 7.5$ (s).

From 3.4-dimethylbenzenediazonium tetrafluoroborate: The standard procedure above was repeated except the use of 3.4-dimethy lbenzenediazonium tetrafluoroborate $(0.90 \mathrm{~g}$. $4.85 \mathrm{mmol})$ to obtain 1-bromo-3.4-dimethylbenzene (0.187 g. $21 \%$ ). GC/MS $183\left(\mathrm{M}^{-}\right) 171.143,117.105,89,77,51$, 39.

From 4-nitrobenzenediazonium tetrafluoroborate: The standard procedure above was repeated except the use of 4nitrobenzenediazonium tetrafluoroborate $(1.15 \mathrm{~g} .4 .85$ mumol) to obtain 4-bromonitrobenzene $(0.98 \mathrm{~g} .100 \%) . \mathrm{mp}$ $125-128^{\circ} \mathrm{C}$ (lit. mp 124-126 ${ }^{\circ} \mathrm{C}$ ): GC/MS $200\left(\mathrm{M}^{+}\right) 173.157$. $156,75.50,38:{ }^{1} \mathrm{H}$ NMR (DMSO- $\left.d_{6}\right) \delta 7.9$ (d. $J=9.2 \mathrm{~Hz}$, $2 \mathrm{H}) .8 .2(\mathrm{~d} . J=9.2 \mathrm{~Hz} .2 \mathrm{H})$.

From 4-nitrobenzenediazonium tetrafluoroborate: The standard procedure above was repeated except the use of 4nitrobenzenediazonium tetrafluoroborate $(0.74 \mathrm{~g} .3 .1 \mathrm{mmol})$ and $\mathrm{Me}_{2} \mathrm{SCuCl}(0.5 \mathrm{~g} .3 .1 \mathrm{mmol})$ to obtain 4-chloronitrobenzene $\left(0.30 \mathrm{~g} .62 \%\right.$ ). $\mathrm{mp} 82.85^{\circ} \mathrm{C}$ (lit. $\mathrm{mp} 80-83^{\circ} \mathrm{C}$ ): $\mathrm{GC} /$ MS $156\left(\mathrm{M}^{-}\right) 157,127,111.113,85.75 .63,50,37:{ }^{1} \mathrm{H}$ 
NMR (DMSO-d $\left.d_{\text {) }}\right) \delta 7.76(\mathrm{dd}, J=9.2 \mathrm{~Hz}, J=2.2 \mathrm{~Hz}, 2 \mathrm{H}$ ), $8.28(\mathrm{dd}, J=9.2 \mathrm{~Hz}, J=2.3 \mathrm{~Hz}, 2 \mathrm{H})$.

From 3-chloro-6-methoxy-4-nitrobenzenediazonium tetrafluoroborate: The standard procedure above was repeated except the use of 3-chloro-6-methoxy-4-nitrobenzenediazonium tetrafluoroborate $(1.20 \mathrm{~g} .5 .96 \mathrm{mmol})$ to obtain Ibromo-3-chloro-6-methoxy-4-nitrobenzene $(0.58 \mathrm{~g} .76 \%$ ). mp 100-102 ${ }^{\circ} \mathrm{C}$ : GC/MS $267\left(\mathrm{M}^{+}\right), 237,206,178,176,141$, $112,97,62,53:{ }^{1} \mathrm{H}$ NMR (DMSO- $\left.d_{h}\right) \delta 4.0(s, 3 \mathrm{H}), 7.4(s$, IH), $8.4(s, \mathrm{IH})$.

From 2-methoxybenzenediazonium tetrafluoroborate: The standard procedure above was repeated except the use of 2methoxybenzenediazonium tetrafluoroborate $(1.15 \mathrm{~g}, 4.85$ mmol) to obtain 2-bromoanisole $(0.13 \mathrm{~g}, 16 \%)$. ${ }^{1} \mathrm{H}$ NMR (DMSO- $\left.d_{6}\right) \delta 3.7(s, 3 \mathrm{H}), 6.6-7.3(m, 4 \mathrm{H})$.

From 4-methylbenzenediazonium tetrafluoroborate: The standard procedure above was repeated except the use of 4methylbenzenediazonium tetrafluoroborate $(1.15 \mathrm{~g}, 4.85$ mmol) to obtain 4-bromotoluene (0.18 g. 24\%). mp 25-28 ${ }^{\circ} \mathrm{C}$ (lit, mp 26-29 ${ }^{\circ} \mathrm{C}$ ).

From 4-methoxybenzenediazonium tetrafluoroborate: The standard procedure above was repeated except the use of 4methoxybenzenediazonium tetrafluoroborate $(1.15 \mathrm{~g} .4 .85$ minol), to obtain 4-bromoanisole $(0.14 \mathrm{~g}, 18 \%)$. ' $\mathrm{H}$ NMR (DMSO- $\left.d_{1}\right) \delta 3.7(s, 3 \mathrm{H}), 6.7(d, 2 \mathrm{H}), 7.3(d, 2 \mathrm{H})$.

\section{Results and Discussion}

Preparation of $\mathrm{Me}_{2} \mathrm{SCuX}(\mathrm{X}=\mathrm{Cl}, \mathrm{Br})$. According to our recent findings that dimethyl sulfide and methyl bromide etc. were efficiently produced from a solution of benzyl bromide in DMSO upon heating. "we set out hopefully to utilize those in situ generated volatile chemicals into a more useful compound. And we were able to obtain $\mathrm{Me}_{2} \mathrm{SCuX}$ when we added $\mathrm{Cu}(0)$ to a solution of benzyl bromide (benzyl chloride) and DMSO maintaining at $120^{\circ} \mathrm{C}$ for $5 \mathrm{~h}$. Table 1 shows the high isolated yields $(77-89 \%)$ of the complexes $\mathrm{Me}_{2} \mathrm{SCuBr}$ we obtained. However yield of $\mathrm{Me}_{2} \mathrm{SCuCl}$ obtained from a solution of benzyl chloride in DMSO was low $(18 \%$, entry 2$)$ reflecting the low reactivity of chlorides compared to that of bromides. We have previously noted this similar low reactivity of benzyl chloride compared to that of benzyl bromide in the preparation of trimethylsulfonium halide from a solution benzyl halide in DMSO. ${ }^{6}$
Table 1. Preparation of $\mathrm{Mc} \mathrm{C}_{2} \mathrm{SCuX}$

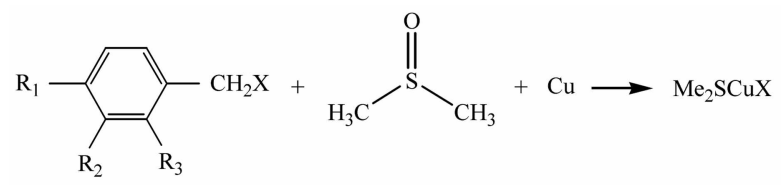

\begin{tabular}{|c|c|c|}
\hline Fintry & Bensyl halide & Yield $(\%)^{r}$ \\
\hline 1 & $\mathrm{R}_{1}=\mathrm{R}_{2}=\mathrm{R}_{2}=11, \mathrm{X}=13 \mathrm{r}$ & 77 \\
\hline 2 & $\mathrm{R}_{1}=\mathrm{R}_{2}=\mathrm{R}_{3}=\mathrm{II} . \mathrm{X}=\mathrm{Cl}$ & 18 \\
\hline 3 & $\mathrm{R}_{1}=\mathrm{NO}_{2} \cdot \mathrm{R}_{2}=\mathrm{R}_{3}=1 \mathrm{I}, \mathrm{X}=13 \mathrm{r}$ & 85 \\
\hline 4 & $\mathrm{R}_{1}=\mathrm{R}_{2}=\mathrm{II} . \mathrm{R}_{3}=\mathrm{NO}_{\underline{2}} \mathrm{X}=\mathrm{l} 3 \mathrm{r}$ & 87 \\
\hline 5 & $\mathrm{R}_{1}=\mathrm{Cl}_{3} \mathrm{R}_{2}=\mathrm{R}_{3}=\mathrm{Il}, \mathrm{X}=\mathrm{Br}$ & 88 \\
\hline 6 & $\mathrm{R}_{1}=\mathrm{R}_{2}=\mathrm{Il}, \mathrm{R}_{3}=\mathrm{CII}_{3}, \mathrm{X}=\mathrm{Br}$ & 89 \\
\hline 7 & $\mathrm{R}_{1}=\mathrm{R}_{2}=\mathrm{Il}, \mathrm{R}_{3}=\mathrm{Cl}, \mathrm{X}=\mathrm{Br}$ & 78 \\
\hline
\end{tabular}

"Isolated yield.

Remarks needs to be mentioned about the present method of $\mathrm{Me}_{2} \mathrm{SCuX}$. First of all it is unique in that volatile and flammable chemicals (methyl bromide and dimethyl sulfide) are conveniently produced and utilized from common safe chemicals such as bromide, DMSO, and $\mathrm{Cu}(0){ }^{6}{ }^{6}$ Secondly the method is a consecutive one-pot reaction of useful reagents. That is, $\mathrm{Cu}(0)$ is oxidized to $\mathrm{Cu}(\mathrm{l})$, followed by forming complex with dimethyl sulfide, generated in situ.

Formation mechanism of $\mathrm{Me}_{2} \mathrm{SCuBr}$. Kornblum reaction is an oxidation of benzyl bromide to benzaldehyde by DMSO in basic aqueous conditions." ${ }^{\text {. }} 11$ However, in the absence of both a base and water, Kornblum reaction cleanly afforded trimethylsulfonium bromide in excellent isolated yields $(65-100 \%)$ depending on substituents in benzyl bromide. $^{6.12}$

In order to explain high quantitative yields of trimethylsulfonium bromide it was proposed that methyl bromide and dimethyl sulfide were produced not only from the reaction of Kornblum reaction (Scheme 1) but also from decomposition of DMSO itself. That is, the role of DMSO was explained as both an oxidant and a masked precursor for methyl bromide and dimethyl sulfide as was described by Ganem et al. ${ }^{1.3}$ Scheme 1 shows the pathways operating in the reaction of benzyl bromide and DMSO as was proposed by Park et al.. ${ }^{6}$

In the presence of $\mathrm{Cu}(0)$, however, other simultaneous reactions, in addition to those shown in Scheme 1. proceeded. i.e. oxidations of $\mathrm{Cu}(0)$ in reacting with both methyl

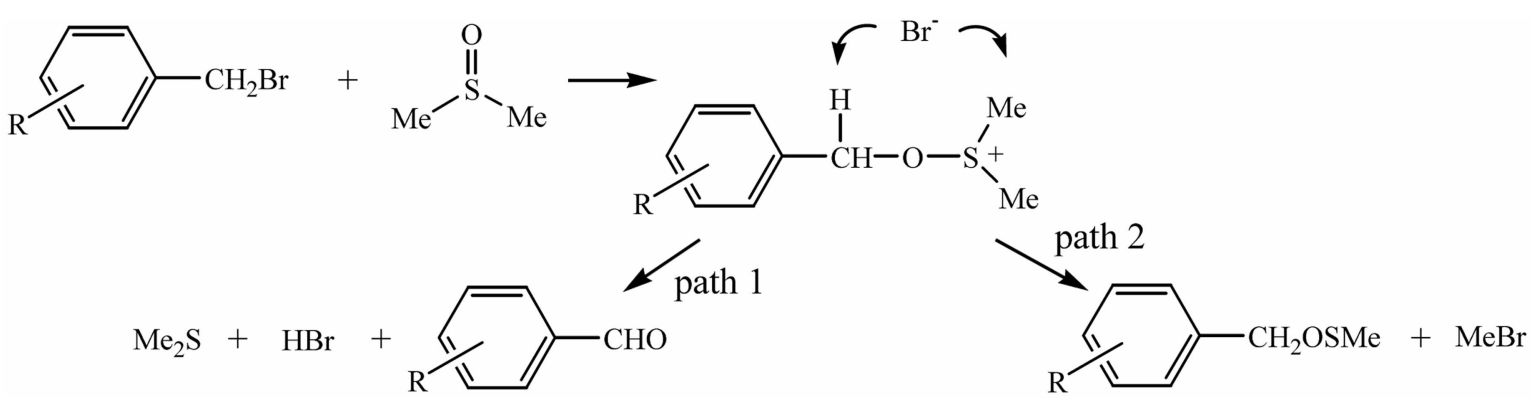

Scheme 1. Pathways in the reaction of benzyl bromide and DMSO." 


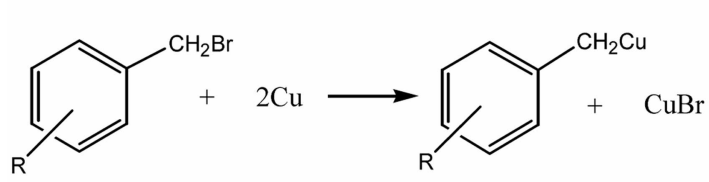

Scheme 2. Oxidation of Cur(0) by benzyl bromide. ${ }^{14}$

Table 2. Ilalogenation of dianonium tetralluoroborate with MetSCuX

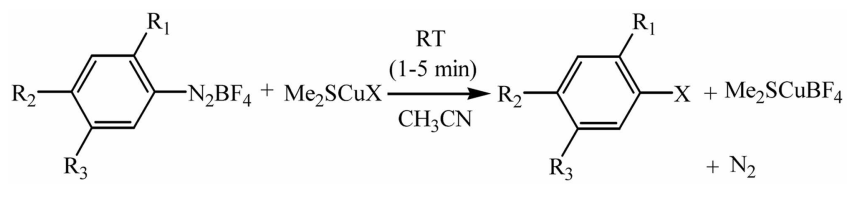

\begin{tabular}{|c|c|c|}
\hline Entry: & Diazonium compounds & Yicld $(\%)^{\omega}$ \\
\hline 1 & $\mathrm{R}_{1}, \mathrm{R}_{2} \cdot \mathrm{R}_{3}: \mathrm{II} . \mathrm{X} \mathrm{I3r}$ & 75 \\
\hline 2 & $\mathrm{R}_{1} \quad \mathrm{R}_{2} \mathrm{I}, \mathrm{R}_{3} \mathrm{NO}_{2} \times \mathrm{X} \mathrm{l3r}$ & 73 \\
\hline 3 & $\mathrm{R}_{1} \mathrm{R}_{3}$ II. $\mathrm{R}_{2} \mathrm{IBr} \times \mathrm{Br}$ & 78 \\
\hline 4 & 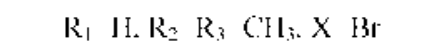 & 21 \\
\hline 5 & $\mathrm{R}_{1} \mathrm{R}_{2} \quad \mathrm{H}, \mathrm{R}_{2} \mathrm{NO}_{2} \times \mathrm{X} \mathrm{Br}$ & 100 \\
\hline 6 & $\mathrm{R}_{1} \mathrm{R}_{3} \mathrm{II} . \mathrm{R}_{2} . \mathrm{NO}_{2} \times \mathrm{Cl}$ & 62 \\
\hline 7 & $\mathrm{R}_{1} \mathrm{OCH}_{3}, \mathrm{R}_{2} \mathrm{NO}_{2}, \mathrm{R}, \mathrm{Cl} \times \mathrm{X} 3 \mathrm{r}$ & 76 \\
\hline 8 & $\mathrm{R}_{1} O \mathrm{OCH}_{3} \mathrm{R}_{2} \mathrm{R}_{3} \mathrm{II} \times \mathrm{Br}$ & 16 \\
\hline 9 & $\mathrm{R}_{1} \mathrm{R}_{3} \mathrm{II} . \mathrm{R}_{2} \mathrm{CH}_{3} \times \mathrm{Br}$ & 24 \\
\hline 10 & $\mathrm{R}_{1} \mathrm{R}_{3}$ HI. $\mathrm{R}_{2} \mathrm{OCI} \mathrm{I}_{3} \times \mathrm{Br}$ & 18 \\
\hline
\end{tabular}

"Isolated yield.

bromide (in situ generated product) and benzyl bromide (starting material), similarly as was observed in the literature (Scheme 2). ${ }^{1 \cdot 1}$

In fact we confirmed the formation of bibenzyl in our reaction by $\mathrm{GC} / \mathrm{MS}$ analysis, strongly supporting the same pathway as shown in Scheme 2. In addition to the benzyl bromide, methyl bromide produced from the reaction of benzyl bromide and DMSO in our conditions (Scheme 1) would also induce oxidation of $\mathrm{Cu}(0)$ to $\mathrm{CuBr}$ as was shown in Scheme 2. CuBr prepared in situ would make a $\mathrm{Me}_{2} \mathrm{SCuX}$ by complexing with dimethyl sulfide.

Application of $\mathrm{Me}_{2} \mathrm{SCuX}(\mathrm{X}=\mathbf{C}, \mathrm{B}, \mathrm{Br})$. We carried out Sandmeyer reactions with $\mathrm{Me}_{2} \mathrm{SCuX}$ and arenediazonium tetrafluoroborates. ${ }^{\text {aa }}$ Sandmeyer reactions generally conducted in aqueous conditions, are utilized for many purposes such as in hydroxylation and halogenation $e t .^{15}$. The present study revealed that $\mathrm{Me}_{2} \mathrm{SCuX}$ freshly prepared by our method was very effective in displacing tetrafluoroborate group with halogen under mild conditions and in acetonitrile. i.e. the reactions were completed within $5 \mathrm{~min}$ at room temperature with vigorous evolution of nitrogen as is shown in lable 2 . Considering the heterogeneous reaction mixture due to low solubility of $\mathrm{Me}_{2} \mathrm{SCuX}$ in acetonitrile. the moderate to high isolated yields in Table 2 support the very efficient reaction between $\mathrm{Me}_{2} \mathrm{SCuX}$ and arenediazonium tetrafluoroborates.

\section{Conclusion}

We were able to discover an another preparative method of $\mathrm{Me}_{2} \mathrm{SCuX}(\mathrm{X}=\mathrm{Cl}, \mathrm{Br}$ ) via one-pot reaction from safe and common chemicals such as Cu, benzyl halide, and DMSO. Also we found out that heterogeneous reaction of $\mathrm{Me}_{2} \mathrm{SCuX}$ and arenediazonium tetrafluoroborate in acetonitrile was so rapid and effective to afford corresponding bromoaromatics. For an instance $100 \%$ isolated yield was obtained from the reaction of $\mathrm{Me}_{2} \mathrm{SCuBr}$ and 4-nitrobenzenediazonium tetrafluoroborate.

Acknowledgment. This study was financially supported by research fund of Chungnam National University in 2006.

\section{References}

1. (a) Danes. A. M.: Abell. A. D. Org. Bionol Chem. 2004. 2. 2371 2375. (b) Baldwits. J. E.: Spives. A. C.: Schoticld. C. J.: Swecney; J. B. Tetrahedron 1993, t9, 6309-6330.

2. Khavitonov. D. N. Russ. I. Coord (hem. 1996, 22,668-670.

3. Ilouse. I1. O.: Chu. C.-Y.: Wilkins. J. M.: I Jmen. M. I. I. Org. Chem. 1975. $40.1460-1469$.

4. Wuls. I'. G M. Sinth. Comman. 1981. //(2). 139-140.

5. Theis. A. B.: Townsend. C. A. Simh. Commum. 1981. //(2). 157166.

6. Park. K. H1: So, M. S.: Kim. Y. W, Bull Korean Chem. Soc. 2005. $26,149]-1492$.

7. Kokoreva. S. G: Nifontowa. G. A.: Korableva L. G: Sikorenko. Y. B.: Laventev. I. P. 2h. Alorg. Nhm. 1995. fo. 1320-1324.

8. (a) Park. K. H.: Cho. Y. H.: Jang. E. I. Butl. Nonew Chen. Soc. 1996, I7(2), 179-182, (b) Roc. A. Org. React 1952, 5. 193.

9. Kornblum. A.: Jones. W. I. Anderson. (i I. f. tm. (Tem. Soc. 1959. $81.4113-4114$.

10. Nace. H. R.: Monagle. J. J. J. Org. Chem. 1959. 24. 1792-1793.

11. Helm. A.: Heiler. D.: MeLendon. G. J. Am. Chem. Soc. 1957. It $6227-6238$.

12. Inpublished work. Manuscript in preparation.

13. Gaujem. B.: I3oeckman .Ir.. R. K. Tetrahedron Lett. 1974. //. 917920 .

14. Ebert. G W.: Rjeke. R. D. J. Ogg. (hem. 1984. 19. 5280-5282.

15. Chu. C.-K.: Kim. J.-H.: Kim. D. W.: Chung. K.-Y.: Katzenellenbogen. 1. A.: Chi. D. Y. Bull. Korew (hem. Soc 2005, 26, 599-602. 